\title{
Why rare tropical cyclone formation after maturity of super El Niño events in the western North Pacific?
}

\author{
Yi-Xian $\mathrm{Li}^{1,2}$ and Jia-Yuh $\mathrm{Yu}^{2, *}$ \\ ${ }^{1}$ Earth System Science, Taiwan International Graduate Program and Research Center in Environmental Change, Academia \\ Sinica, Taipei City, Taiwan \\ ${ }^{2}$ Department of Atmospheric Sciences, National Central University, Taoyuan City, Taiwan
}

\section{Article history: \\ Received 13 January 2019 \\ Revised 17 June 2019 \\ Accepted 23 June 2019}

Keywords:

Seasonal genesis parameter, Super El

Niño, Anomalous Walker circulation

\section{Citation:}

Li, Y.-X. and J.-Y. Yu, 2020: Why rare tropical cyclone formation after maturity of super El Niño events in the western North Pacific? Terr. Atmos. Ocean. Sci., 31, 21-32, doi: 10.3319/ TAO.2019.06.23.01

\begin{abstract}
Using Gray's "seasonal genesis parameter" (SGP) as a metric, we investigate the large-scale environmental factors and the associated circulation changes attributing to rare tropical cyclone (TC) formation in the western North Pacific (WNP) in the first-half years of 1983,1998 , and 2016, which are known to be the decaying phase of the 1982/83, 1997/98, and 2015/16 super El Niño events. A budget analysis of SGP shows that decreases in relative vorticity and specific humidity, due to the existence of a Philippine Sea anticyclonic anomaly, are the major factors attributing to strong suppression of TC formation mentioned above. From a broader basin-scale view, we demonstrate that this Philippine Sea anticyclone could also be a response resulting from the descending branch of a northwest-and-southeast tilting anomalous overturning (Walker) circulation forced by asymmetric SST anomalies typical of the Cold Tongue El Niño.
\end{abstract}

\section{INTRODUCTION}

Each year, about 26 tropical cyclones (TCs) reaching tropical storm intensity form in the western North Pacific (WNP) basin, accounting for approximately $30 \%$ of the total number of TCs around the globe. It has long been recognized that El Niño/Southern Oscillation (ENSO) exerts great impacts on frequency and genesis location of TCs. During the developing phase of ENSOs, although the total number of TCs tends to increase in the WNP, there are generally fewer (more) TCs to the west (east) of $140-160^{\circ} \mathrm{E}$ and to the north (south) of $15-20^{\circ} \mathrm{N}$ (Lander 1994; Chen et al. 1998; Wang and Chan 2002), exhibiting a southeastward shift of the TC formation pattern. During the decaying phase of ENSOs, nonetheless, a below-normal TC genesis frequency often occurs from January to July in the WNP (Chan 2000; Wang and Chan 2002).

Several mechanisms have been proposed to explain how ENSOs influence TC formation in the WNP, including changes in (1) Walker circulation (Chan 1985; Kim et

\footnotetext{
* Corresponding author

E-mail:jiayuh@atm.ncu.edu.tw
}

al. 2011), (2) monsoon trough (Chen et al. 1998; Wu et al. 2012), (3) Pacific Tropical Upper Tropospheric Trough (TUTT), and (4) large-scale environmental factors (Camargo et al. 2007). Changes in structure and strength of Walker circulation directly influence TC formation pattern. A weakened Walker circulation during the warm phase of ENSOs tends to suppress TC frequency in the WNP. Changes in the intensity of monsoon trough also play a crucial role in modulating TC frequency in the WNP since about three quarters of TCs form within or near the monsoon trough (Chen et al. 2004; Molinari and Vollaro 2013). Some studies suggested that the eastward shift of TC genesis pattern during El Niño can be attributed to an eastward extension of the monsoon trough (Lander 1994; Chen et al. 1998; Chia and Ropelewski 2002) because changes in Walker circulation and monsoon trough often coexist. Recent studies (Wu et al. 2015; Wang and Wang 2019) found that the "trans-basin" SST anomalies can alter the position of Pacific TUTT, which in turn shift the TC genesis locations over the WNP with suppressed (enhanced) TC formation in the eastern (western) portion of the Pacific TUTT due to the enhanced 
(decreased) vertical wind shear.

Gray (1977) first designed an empirical index called "seasonal genesis parameter" (SGP) to associate the environmental factors with TC genesis potential. In Gray's pioneer work, SGP is defined as a product of six largescale environmental factors, including "relative vorticity", "Coriolis force", "vertical wind shear", "upper ocean heat content", "atmospheric stability", and "mid-troposphere humidity" effects. A number of indices were later developed by modifying some of the environmental factors to represent the TC genesis potential. These indices include "yearly genesis parameter" (Royer et al. 1998), "genesis parameter" (DeMaria et al. 2001), "genesis potential index" (Emanuel and Nolan 2004), "genesis potential parameter" (Kotal et al. 2009), "tropical cyclone genesis index (Tippett et al. 2011), "cyclone genesis index" (Bruyère et al. 2012); and all of which have demonstrated certain degrees of success in selected ocean basins.

Since most El Niño events decay quickly in spring, their impacts on TC formation in the first-half calendar year are expected to be modest. In this study, we utilize the Gray's SGP to investigate the large-scale environmental factors and circulation changes leading to rare TC formation in the WNP during the first-half years of 1983, 1998, and 2016, which are known to be the decaying phase of the 1982/83, 1997/98, and 2015/16 super El Niño events. In section 2, a brief introduction of data used and the definition of SGP are presented, along with a special transformation of SGP for conducting budget analysis. We present and discuss the budget results and circulation changes in section 3. Major findings are concluded and discussed in section 4 .

\section{DATA AND METHODOLOGY}

\subsection{Data Sources}

The best-track TC data generated by the Joint Typhoon Warning Centre (JTWC) are used to demonstrate the historical TC formation in the WNP. This JTWC best-track data provide location and intensity (typically the maximum 1-minuite mean sustained wind) of each TC at six-hour intervals from 1949 to the present. As in our previous works (Yu et al. 2009; Yu and Chiu 2012), only those TCs reaching at least the tropical storm intensity (the maximum sustained wind speed $\geq 35$ knots) are counted.

To calculate the environmental factors in SGP, the ERA-Interim reanalysis data produced by ECMWF (European Centre for Medium-Range Weather Forecast) with an improved atmospheric model and assimilation system are adopted (Dee et al. 2011). The ERA-interim dataset provides a global coverage of major meteorological parameters at surface and 37 pressure levels from 1979 to the present. The ocean temperature data from the Global Ocean Data Assimilation System (GODAS) archived in the Earth System Research Laboratory of National Oceanic and Atmo- spheric Administration (NOAA) are also used to calculate the upper ocean heat content. The data analysis period is from 1980 to 2016 , and all data were mapped onto $5^{\circ} \times 5^{\circ}$ grids prior to the calculation of all environmental factors.

\subsection{Seasonal Genesis Parameter}

The Gray's SGP is defined as a product of six largescale environmental factors (including 3 dynamic and 3 thermodynamic effects) to reproduce the TC genesis potential in the WNP, which gives

$\mathrm{SGP}=\left(Z_{r}+5\right) \times(f) \times\left(\frac{1}{S_{Z}+5}\right) \times(\mathrm{STF}) \times\left(\frac{\partial \theta_{e}}{\partial p}+5\right) \times \mathrm{RH}(1)$

where $Z_{r}$ denotes the relative vorticity at $950 \mathrm{hPa}, f$ the Coriolis parameter, and $S_{Z}$ the vertical wind shear between 950 and $200 \mathrm{hPa}$ levels. STF represents the sea temperature factor associated with the effect of upper ocean heat content, imposed with a minimum sea surface temperature (SST) threshold of $79^{\circ} \mathrm{F}$. The vertical gradient of equivalent potential temperature, $\left(\frac{\partial \boldsymbol{\theta}_{e}}{\partial p}\right)$, taken between surface and $500 \mathrm{hPa}$, represents the effect of atmospheric stability. RH denotes the mean relative humidity between 700 and $500 \mathrm{hPa}$. For more details of SGP (e.g., formulation of STF, units of all terms, etc.), please refer to section 4 of Gray (1977).

Following Yu et al. (2018), we take a binary-logarithm on Eq. (1) to yield

$\mathrm{cSGP}=\mathrm{cRV}+\mathrm{cCO}+\mathrm{cWS}+\mathrm{cST}+\mathrm{cAS}+\mathrm{cRH}$

where cSGP $=\log _{2} \mathrm{SGP}, \mathrm{cRV}=\log _{2}\left(\mathrm{Z}_{\mathrm{r}}+5\right), \ldots$, and so on. We note that, under such a simple transformation, the size of SGP becomes a linear addition of six environmental factors. We further take an average of Eq. (2) over the study period (1980 - 2016) to yield

$c \overline{\mathrm{SGP}}=c \overline{\mathrm{RV}}+c \overline{\mathrm{CO}}+c \overline{\mathrm{WS}}+c \overline{\mathrm{ST}}+c \overline{\mathrm{AS}}+c \overline{\mathrm{RH}}$

where the overbar in Eq. (3) represents the long-term mean (climatology) of the underlying variable.

Subtracting Eqs. (3) from (2), we get an anomaly equation governing SGP changes, i.e.,

$\mathrm{cSGP}^{\prime}=\mathrm{cRV}^{\prime}+\mathrm{cSHR}^{\prime}+\mathrm{cSTF}^{\prime}+\mathrm{cSTB}^{\prime}+\mathrm{cRH}^{\prime}$

where $\mathrm{cSGP}^{\prime}=\log _{2} \frac{\mathrm{SGP}}{\overline{\mathrm{SGP}}}, \mathrm{cRV}^{\prime}=\log _{2} \frac{\mathrm{RV}}{\mathrm{RV}}, \ldots$, and so on. As shown, only five factors contribute to changes of SGP since the Coriolis factor is fixed in time. Accordingly, a positive (negative) value of cSGP' implies an above-normal (below-normal) condition of the TC genesis potential, with 
the size determined by changes of environmental factors on the right-hand side of Eq. (4). One should note that such a transformation provides a simple, quantitative measure of each factor's contribution to the TC genesis potential.

\section{RESULTS}

\subsection{Analysis of Indices}

Figure 1 displays the semi-yearly (6-monthly) time series of NTC (Number of TC formation) and MEI (multivariate ENSO index) in the WNP during the period from 1980 to 2016. Giving a huge contrast of the mean NTC between the first- and the second-half years (4.5 vs. 21.3), the correlation between NTC and MEI appears to be robust for the first-half-year period $(\gamma=-0.37)$ compared to the secondhalf-year period $(\gamma=0.14)$, which could be sensitive to the type of ENSO as Wang et al. (2019) found a closer link for strong ENSOs. The correlation coefficient for the former period tends to increase when MEI leads NTC for months (see Fig. A1 in Appendix A), indicating a suppression of TC formation from spring to early summer after maturity of ENSO events. For example, NTC in the first-half years of 1983,
1987, 1992, 1998, 2007, 2010, and 2016 (i.e., the decaying phases of the 1982/83, 1986/87, 1991/92, 1997/98, 2006/07, $2009 / 10$, and $2015 / 16$ ENSOs) are all well below the mean NTC of 4.5 . Besides, among the aforementioned ENSO events, three have been recognized as super cases (i.e., 1982/83, 1997/98, and 2015/16), with MEI values 2 standard deviations above the mean for more than six months. Surprisingly, no TC formed in the first-half years of 1998 and 2016 and only one weak TC case occurred in the first-half year of 1983, implying a significant suppression of TC formation during the decaying phase of strong El Niño events.

To understand what factors contribute to the rare TC formation mentioned above, we conduct a budget analysis of SGP using Eq. (4) for the first-half-year period, averaged over the "major developing region" (MDR) $\left(5-20^{\circ} \mathrm{N}\right.$; $\left.110-180^{\circ} \mathrm{E}\right)$. As shown in Fig. 2, significant fluctuations of $\mathrm{cSGP}^{\prime}$ occur throughout the study period, with alternate appearances of positive and negative anomalies. In general, those years with negative (positive) values of cSGP' are associated with fewer (more) NTC $(\gamma=0.5)$, implying the robustness of SGP in representing the TC genesis potential. The budget results also show that changes in "relative

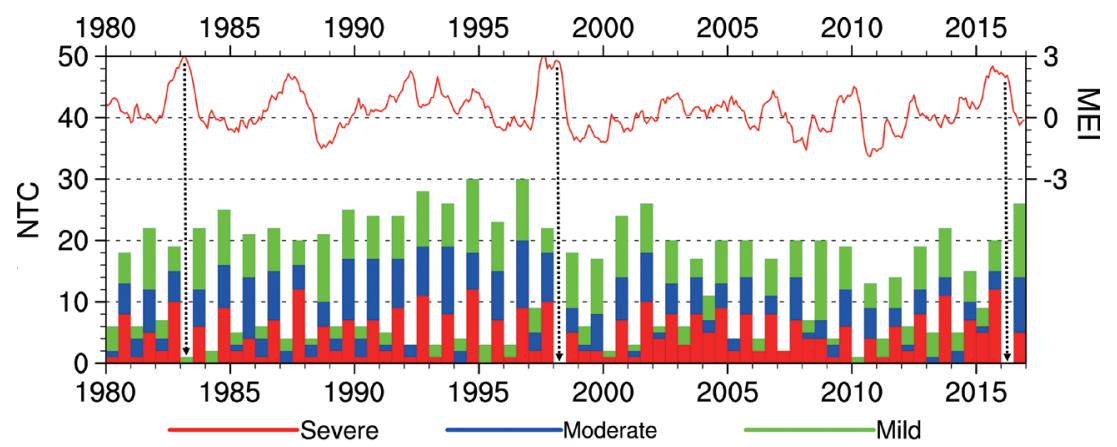

Fig. 1. The semi-yearly (6-monthly) time series of NTC (denoted by the histograms with a scale on the left) and MEI (multivariate ENSO index, denoted by the curve with a scale on the right) during the period from 1980 to 2016 . The NTC is classified into 3 categories according to the intensity of TC: a severe case for $\mathrm{v}_{\max } \geq 96 \mathrm{kt}$, a moderate case for $95 \mathrm{kt} \geq \mathrm{v}_{\max } \geq 64 \mathrm{kt}$ and a mild case for $63 \mathrm{kt} \geq \mathrm{v}_{\max } \geq 34 \mathrm{kt}$. The MEI data were downloaded from the Earth System Research Laboratory (ESRL) of NOAA at https://www.esrl.noaa.gov/psd/enso/mei/table.html.

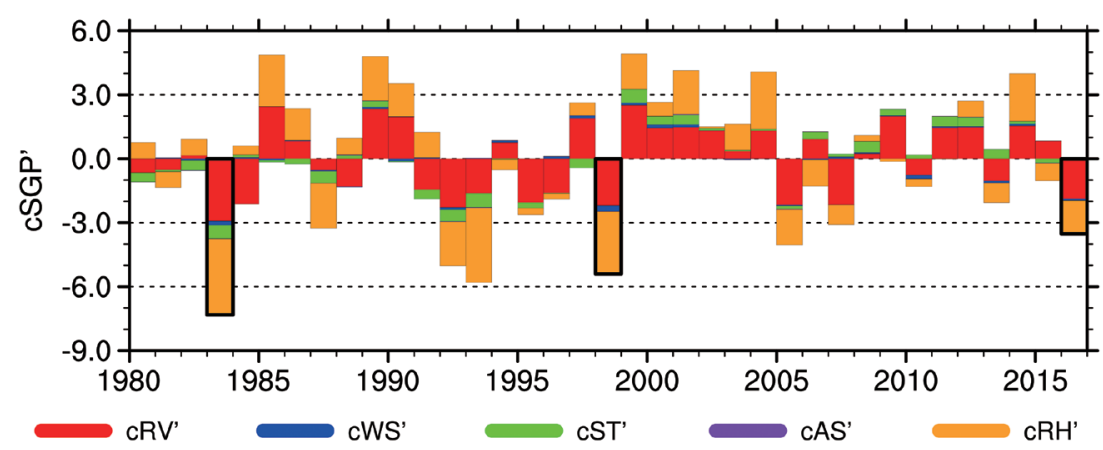

Fig. 2. The time series of $\mathrm{cSGP}^{\prime}$ and its contribution from five environmental factors averaged over the MDR $\left(110-180^{\circ} \mathrm{E} ; 5-20^{\circ} \mathrm{N}\right)$ during the first-half-year period (January to June), with red denoting contribution from relative vorticity effect, blue from wind shear effect, green from sea temperature effect, purple from atmospheric stability effect, and orange from relative humidity effect. The three super El Niño event years (1983, 1998, and 2016) are highlighted in black. 
vorticity" and "specific humidity" appear to be the two major factors attributing to the large negative anomalies of cSGP' in 1983, 1998, and 2016, together accounting for about $88.3,94.4$, and $96.8 \%$ of the total changes, respectively. Contributions from other environmental factors, e.g., "vertical wind shear", "atmospheric stability", and "upper ocean heat content", are relatively small.

Figure 3 shows the spatial distribution of $\mathrm{cSGP}^{\prime}$ and the associated changes in environmental factors, composited over the first-half years of 1983, 1998, and 2016. As shown, large negative anomalies of $\mathrm{cSGP}^{\prime}$ occur over the MDR (5 $-20^{\circ} \mathrm{N}, 110-180^{\circ} \mathrm{E}$ ) and the subtropical Pacific east of the dateline. As expected, the negative anomalies of $\mathrm{cSGP}^{\prime}$ over MDR come from changes in moisture $\left(\mathrm{cRH}^{\prime}\right)$ and vorticity $\left(\mathrm{cRV}^{\prime}\right)$, both showing a suppression of the TC genesis potential, consistent with results shown in Fig. 2. We also find that, while sea temperature anomalies ( $\left.\mathrm{cST}^{\prime}\right)$ are mostly negative, their magnitudes are relatively small compared to the two leading factors, indicating a modest role played by upper ocean heat content in modulating TC genesis potential. Changes in wind shear (cWS $)$ and atmospheric stability $\left(\mathrm{cAS}^{\prime}\right)$ are negligible when compared to other factors.

\subsection{Changes in Large-Scale Circulation}

To understand what causes decreases in relative vorticity and specific humidity in the first-half years of 1983, 1998, and 2016, we first demonstrate circulation anomalies in the tropical Pacific using composite maps of lower-troposphere $(850 \mathrm{hPa})$ winds and mid-level $(500-700 \mathrm{hPa})$ specific humidity. Here, anomalies are defined as deviations from their climatological means over the period from 1980 to 2016. For ease of diagnosis, the $850 \mathrm{hPa}$ winds are decomposed into the divergent part of winds (denoted by velocity potential) and the rotational part of winds (denoted by stream function). As shown in Fig. 4a for changes in the rotational part of winds at $850 \mathrm{hPa}$ and mid-level moisture, an anomalous anticyclonic circulation prevails over the MDR centred at $\left(14^{\circ} \mathrm{N}, 132^{\circ} \mathrm{E}\right)$. This Phillipine Sea anticyclonic anomaly produces a drier-than-normal environment opposing the TC formation in the WNP, consistent with previous works. For example, previous studies have found the establishment of Philippine Sea anticyclonic anomaly in autumn when a strong ENSO event develops (Wang and Zhang 2002; Chou et al. 2003). Such an anticyclonic anomaly reaches the maximum intensity in the mature phase of ENSO and persists a similar intensity through the ensuing winter and spring to weaken the development of early summer east-Asian monsoon trough, which may further constrain TC genesis frequency in the WNP (Wang and Chan 2002; Wu et al. 2012).

We next expand the analysis domain to cover the entire Pacific for the divergent part of winds (Fig. 4b). As shown, this Philippine Sea anticyclonic anomaly appears to be a response forced by the descending branch of an anomalous overturning (Walker) circulation across the tropical Pacific. We note that the above features exist in individual super ENSO event despite some differences in intensity and locations of ascending/descending centres (see Appendix B for changes in circulation and moisture in 1983, 1998, and 2016, respectively), indicating the robustness of Philippine Sea anticyclonic anomaly after maturity of strong ENSO events. Another interesting feature shown in Figs. $4 \mathrm{~b}$ and B1 is that this anomalous Walker circulation is not at all symmetric about the equator. Instead, it demonstrates a northwest-andsoutheast tilting structure, characterized by an ascending branch centred at $\left(10^{\circ} \mathrm{S}, 125^{\circ} \mathrm{W}\right)$ and a descending branch centred at $\left(5^{\circ} \mathrm{N}, 155^{\circ} \mathrm{E}\right)$. Moreover, the ascending and descending centres shown in Fig. 4b coincide well with the locations of warm and cold SST anomalies shown in Fig. 5a, implying a robust connection between the SST anomalies forcing and the anomalous Walker circulation. Recent studies have pointed out that there are two main types of El Niño events according to the pattern of SST anomalies: namely the "cold tongue El Niño" (CT El Niño) and the "warm pool El Niño" (WP El Niño). The former demonstrates strongest SST anomalies in the eastern Pacific off the coast of South America around $5-10^{\circ} \mathrm{S}$ while the latter exhibits strongest SST anomalies relatively symmetric about the equator near the international dateline (Kug et al. 2009; Ren and Jin 2011; Hu et al. 2012).

Figure 5 shows the SST anomalies composited for the three super El Niño events (1982/83, 1997/98, and 2015/16) against those for the other El Niño events (1986/87, $1987 / 88,1991 / 92,1994 / 95,2002 / 03,2004 / 05,2006 / 07$, and 2009/10) occurring during the period from 1980 to 2016. The composited SST anomalies over the first-half-year period (JFMAMJ) for super El Niño events (Fig. 5a) exhibit a pattern very similar to those of the CT El Niño, with the greatest SST warming occurring over the eastern Pacific. On the other hand, the other El Niño events (Fig. 5b) display SST anomalies pattern typical of the WP El Niño, with the greatest SST warming appearing over the central Pacific. As documented in Ma and Yu (2014), a CT El Niño (or "EP El Niño" in their paper) warming pattern tends to reverse the Walker circulation while a WP El Niño (or "CP El Niño" in their paper) warming pattern would have a better link to the Hadley circulation.

To contrast the decay trend between the two types of El Niño, we plot composited SST anomalies in early summer (AMJ). As shown in Fig. 5c, super El Niño events (CT El Niño) may maintain a similar amplitude of SST warming until early summer while the other El Niño events (WP El Niño) tend to decay quickly after maturity (Fig. 5d). The much slower decay of super El Niño events implies that the tilting anomalous Walker circulation shown in Fig. 4b could be a response resulting from asymmetric SST anomalies forcing typical of the CT El Niño events. 


\section{CONCLUDING REMARKS}

The Gray's SGP (seasonal genesis parameter), defined as a product of six environmental factors, is utilized as a metric to investigate the factors contributing to rare TC formation in the WNP in the first-half years of 1983, 1998, and 2016, which are well known to be the decaying phase of the
1982/83, 1997/98, and 2015/16 super El Niño events. Our study shows that SGP is able to reproduce the yearly variability of NTC (number of TC genesis), at least for the firsthalf-year period, as implied by a sizable negative correlation $(\gamma=-0.37)$ between NTC and MEI (multivariate ENSO index). This negative correlation tends to enhance when MEI leads NTC for months, implying a significant suppression

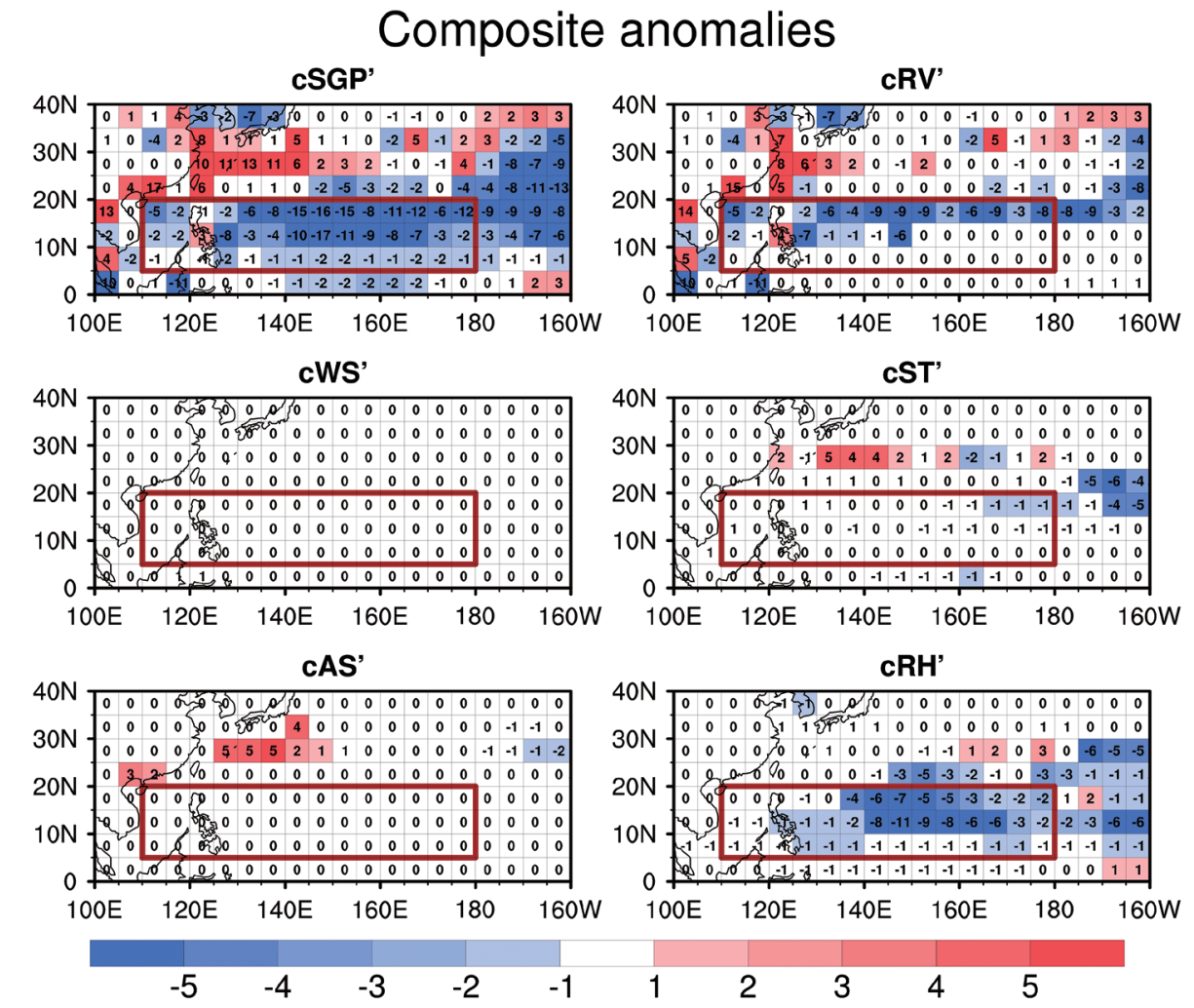

Fig. 3. Spatial distribution of $\mathrm{cSGP}^{\prime}$ and its contribution from five environmental factors, including relative vorticity ( $\left.\mathrm{cRV}^{\prime}\right)$, wind shear $(\mathrm{cWS})$, ocean heat content/sea temperature $\left(\mathrm{cST}^{\prime}\right)$, atmospheric stability $\left(\mathrm{cAS}^{\prime}\right)$, and relative humidity $\left(\mathrm{cRH}^{\prime}\right)$ effects, composited over the first-half-year periods (January to June) of 1983, 1998, and 2016. The rectangular box marks the domain of MDR.

\section{(a) Composite RH / Rotational Winds Anomaly}

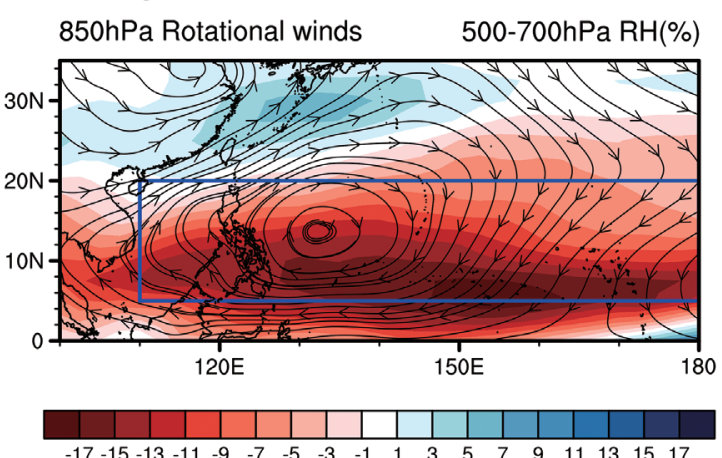

(b) Composite Velocity Potential Anomaly

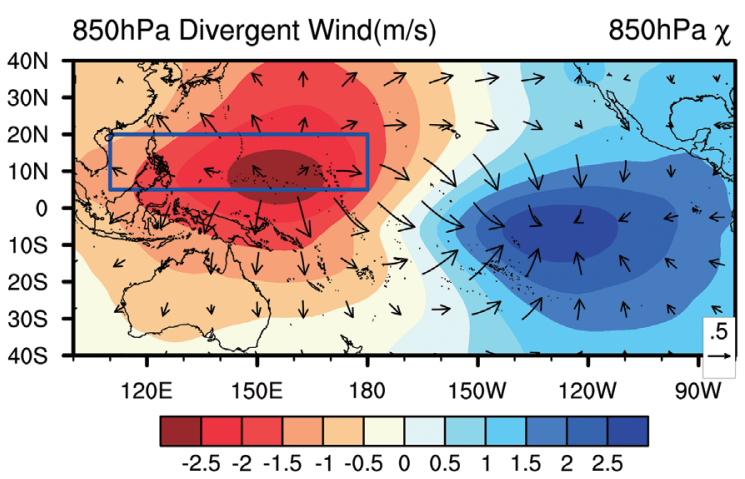

Fig. 4. Anomalies of (a) $850 \mathrm{hPa}$ stream function (contours) and $500-700 \mathrm{hPa}$ relative humidity (shadings) over the western North Pacific (0 $35^{\circ} \mathrm{N}, 100-180^{\circ} \mathrm{E}$ ) and (b) $850 \mathrm{hPa}$ velocity potential (shadings) and divergent winds (vectors) over the entire tropical Pacific $\left(40^{\circ} \mathrm{S}-40^{\circ} \mathrm{N}, 100^{\circ} \mathrm{E}\right.$ $-80^{\circ} \mathrm{W}$ ), composited over the first-half-year periods (January to June) of 1983, 1998, and 2016. Anomalies are defined as deviations from their climatological means over the period from 1980 to 2016. The rectangular boxes mark the domain of MDR. 
(a) JFMAMJ after super El ninos

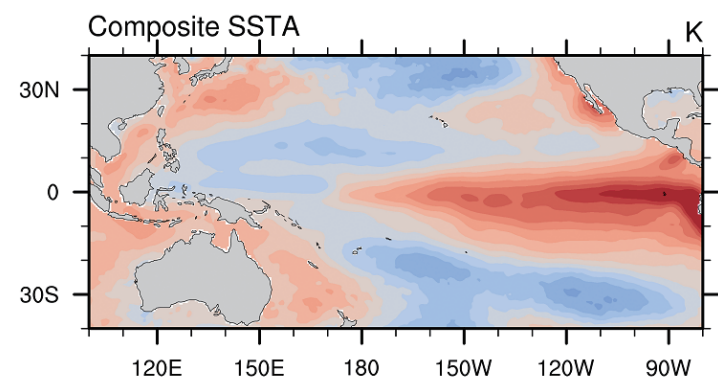

(c) AMJ after super El ninos

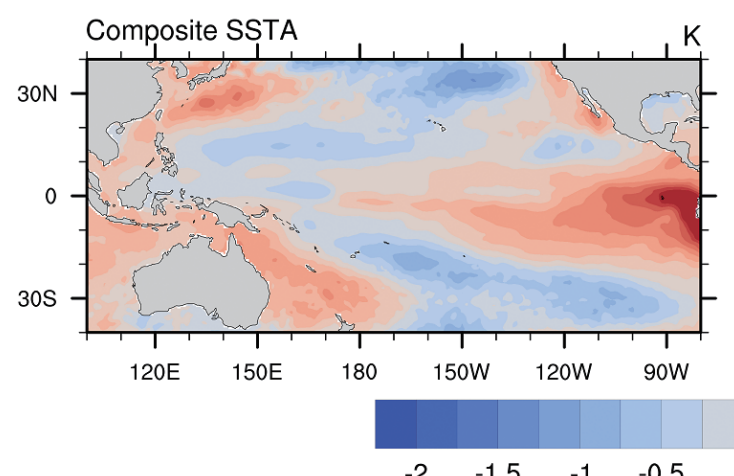

(b) JFMAMJ after other El ninos

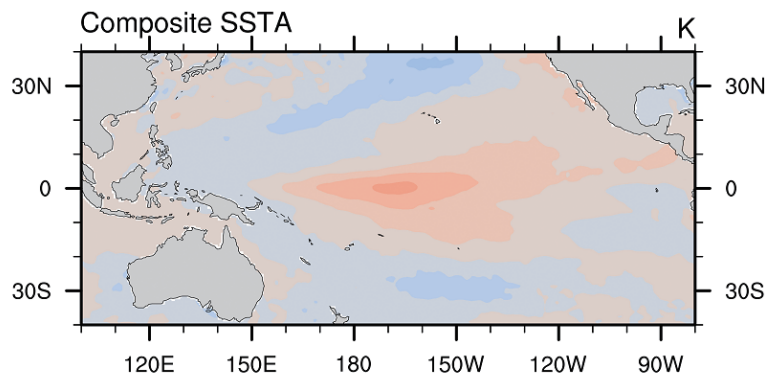

(d) AMJ after other El ninos

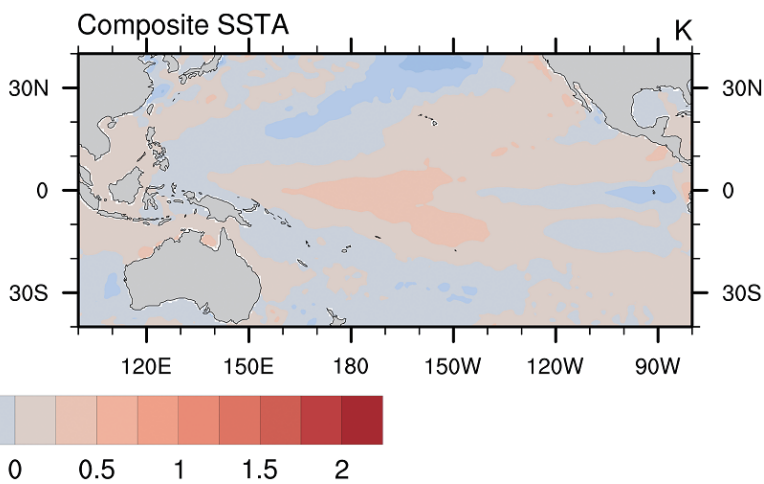

Fig. 5. Sea surface temperature (SST) anomalies composited over the first-half-year period (JFMAMJ) of (a) 1983, 1998, and 2016 for the three super El Niño events and (b) 1987, 1988, 1992, 1995, 2003, 2005, 2007, and 2010 for the other El Niño events during the period from 1980 to 2016. (c) and (d) show the same SST anomalies as in (a) and (b), respectively, but composited only over the early summer of AMJ.

of TC genesis frequency after maturity of ENSO events.

A budget analysis of SGP indicates that decreases in relative vorticity and specific humidity are the two major factors responsible for rare TC formation in the first-half years of 1983, 1998, and 2016. Other environmental factors like vertical wind shear, atmospheric stability and upper ocean heat content appear to play only a modest role in modulating TC formation over the WNP. Analyzing changes in large-scale circulation further shows that the decreased vorticity and humidity should come from the existence of a Philippine Sea anticyclonic anomaly centred at $\left(14^{\circ} \mathrm{N}\right.$, $132^{\circ} \mathrm{E}$ ) as it provides a drier-than-normal environment in the WNP to suppress TC formation. While previous studies have shown that a positive feedback from local atmosphereocean interaction can sustain the Philippine Sea anticyclonic anomaly through the ensuing spring and summer (Wang et al. 2000; Xiang et al. 2013; Wang and Wang 2019), from a broader basin-scale view, we demonstrate that the Philippine Sea anticyclonic anomaly could also be a response resulting from the descending branch of a northwest-andsoutheast tilting anomalous overturning (Walker) circulation due to asymmetric SST anomalies typical of the CT El Niño events (see Fig. 6 for a schematic diagram linking the anomalous Walker circulation with SST anomalies typical of the CT El Niño type).

Although we have demonstrated the advantage of us- ing a simple TC genesis potential index to detect the environmental factors attributing to ENSO-related TC activity changes in the WNP, one should be aware that the use of SGP is accountable only for the first-half-year period. Its performance becomes much poorer when applied to the other period (e.g., July to December). A recent study by $\mathrm{Yu}$ et al. (2018) showed that similar problems exist in other TC genesis potential indices, such as "genesis potential index" (GPI) (Emanuel and Nolan 2004) and several revised versions (Emanuel 2010; Murakami and Wang 2010; Korty et al. 2012; Murakami et al. 2012), due to failure in representing the natural variability of Pacific Decadal Oscillation which is of particular importance to circulation changes on interannual to ineterdecadal timescales across the Pacific (Trenberth 1990; Alexander et al. 1999; Yu and Chang 2014). We also note that the budget results could be sensitive to the metric adopted. For a metric using absolute vorticity as the environmental factor such as the EmanuelNolan GPI (see Appendix C for a detailed discussion), the effect of circulation change will be substantially underestimated, which appears to violate the results presented here.

Acknowledgements This study was sponsored by the Ministry of Science and Technology (MOST) in Taiwan under Grants MOST104-2111-M-008-026-MY2 and MOST1052111-M-008-025-MY3. The Joint Typhoon Warning Centre 


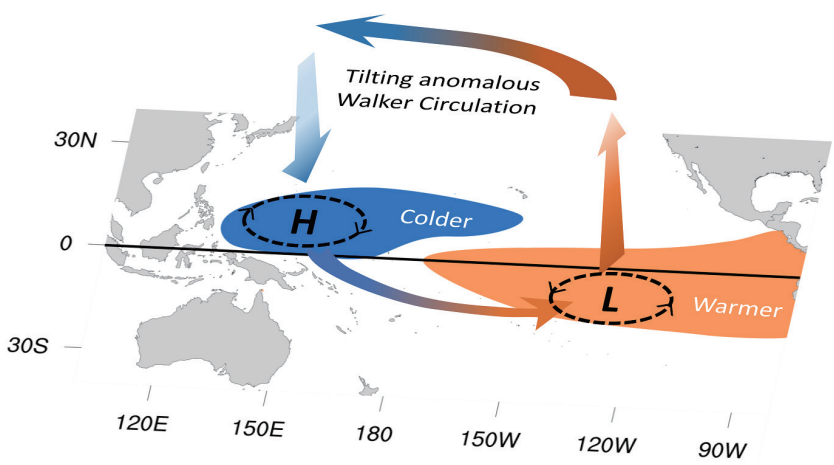

Fig. 6. A schematic diagram depicting the sea surface temperature anomaly pattern and the associated change in Walker circulation over the tropical Pacific during the first-half-year periods (i.e., January to June) of 1983, 1998, and 2016.

(JTWC) best-track tropical cyclone data and the Global Ocean Data Assimilation System data were downloaded, respectively, from the Naval Oceanography Portal at http:// www.metoc.navy.mil/jtwc/jtwc.html?western-pacific and the Earth System Research Laboratory of National Oceanic and Atmospheric Administration (NOAA) at https://www. esrl.noaa.gov/psd/data/gridded/data.godas.html. The ERAinterim atmospheric data were downloaded from the Climate Data Guide under University Corporation for Atmospheric Research (UCAR) at https://climatedataguide.ucar. edu/climate-data. The authors thank the two anonymous reviewers for their many helpful comments to improve the quality of this manuscript.

\section{REFERENCES}

Alexander, M. A., C. Deser, and M. S. Timlin, 1999: The reemergence of SST anomalies in the North Pacific ocean. J. Climate, 12, 2419-2433, doi: 10.1175/1520-0442(1999)012<2419:TROSAI >2.0. $\mathrm{CO} ; 2$. [Link]

Bister, M. and K. A. Emanuel, 2002: Low frequency variability of tropical cyclone potential intensity. 1. Interannual to interdecadal variability. J. Geophys. Res., 107, doi: 10.1029/2001JD000776. [Link]

Bruyère, C. L., G. J. Holland, and E. Towler, 2012: Investigating the use of a genesis potential index for tropical cyclones in the North Atlantic basin. J. Climate, 25, 8611-8626, doi: 10.1175/jcli-d-11-00619.1. [Link]

Camargo, S. J., K. A. Emanuel, and A. H. Sobel, 2007: Use of a genesis potential index to diagnose ENSO effects on tropical cyclone genesis. J. Climate, 20, 4819-4834, doi: $10.1175 /$ jcli4282.1. [Link]

Chan, J. C. L., 1985: Tropical cyclone activity in the Northwest Pacific in relation to the El Niño/Southern Oscillation phenomenon. Mon. Weather Rev., 113, 599-606, doi: 10.1175/1520-0493(1985)113<0599:TCAITN>2 . 0.CO;2. [Link]

Chan, J. C. L., 2000: Tropical cyclone activity over the western North Pacific associated with El Niño and La Niña events. J. Climate, 13, 2960-2972, doi: 10.1175/1520-0442(2000)013<2960:tcaotw>2.0.co;2. [Link]

Chen, T.-C., S.-P. Weng, N. Yamazaki, and S. Kiehne, 1998: Interannual variation in the tropical cyclone formation over the western North Pacific. Mon. Weather Rev., 126, 1080-1090, doi: 10.1175/1520-0493(1998)126<1080:IVITTC >2.0. $\mathrm{CO} ; 2$. [Link]

Chen, T.-C., S.-Y. Wang, M.-C. Yen, and W. A. Gallus, 2004: Role of the monsoon gyre in the interannual variation of tropical cyclone formation over the western North Pacific. Weather Forecast., 19, 776-785, doi: 10.1175/1520-0434(2004)019<0776:rotmgi $>2.0$. co;2. [Link]

Chia, H. H. and C. F. Ropelewski, 2002: The interannual variability in the genesis location of tropical cyclones in the Northwest Pacific. J. Climate, 15, 2934-2944, doi: $10.1175 / 1520-0442(2002) 015<2934$ :tivitg $>2.0$. co;2. [Link]

Chou, C., J.-Y. Tu, and J.-Y. Yu, 2003: Interannual variability of the western North Pacific summer monsoon: Differences between ENSO and Non-ENSO years. $J$. Climate, 16, 2275-2287, doi: 10.1175/2761.1. [Link]

Dee, D. P., S. M. Uppala, A. J. Simmons, P. Berrisford, P. Poli, S. Kobayashi, U. Andrae, M. A. Balmaseda, G. Balsamo, P. Bauer, P. Bechtold, A. C. M. Beljaars, L. van de Berg, J. Bidlot, N. Bormann, C. Delsol, R. Dragani, M. Fuentes, A. J. Geer, L. Haimberger, S. B. Healy, H. Hersbach, E. V. Hólm, L. Isaksen, P. Kållberg, M. Köhler, M. Matricardi, A. P. McNally, B. M. Monge-Sanz, J.-J. Morcrette, B.-K. Park, C. Peubey, P. de Rosnay, C. Tavolato, J.-N. Thépaut, and F. Vitart, 2011: The ERA-Interim reanalysis: Configuration and performance of the data assimilation system. $Q . J$. R. Meteorol. Soc., 137, 553-597, doi: 10.1002/qj.828. [Link]

DeMaria, M., J. A. Knaff, and B. H. Connell, 2001: A 
tropical cyclone genesis parameter for the tropical Atlantic. Weather Forecast., 16, 219-233, doi: 10.1175/1520-0434(2001)016<0219:ATCGPF>2.0. CO;2. [Link]

Emanuel, K., 2010: Tropical cyclone activity downscaled from NOAA-CIRES reanalysis, 1908-1958. J. Adv. Model. Earth Syst., 2, doi: 10.3894/JAMES .2010.2.1. [Link]

Emanuel, K. and D. S. Nolan, 2004: Tropical cyclone activity and the global climate system. 26th Conference on Hurricanes and Tropical Meteorology, Miami, FL., United States, 240-241.

Gray, W. M., 1977: Tropical cyclone genesis in the western North Pacific. J. Meteorol. Soc. Jpn., 55, 465-482, doi: 10.2151/jmsj1965.55.5_465. [Link]

Hu, Z.-Z., A. Kumar, B. Jha, W. Wang, B. Huang, and B. Huang, 2012: An analysis of warm pool and cold tongue El Niños: Air-sea coupling processes, global influences, and recent trends. Climate Dyn., 38, 20172035, doi: 10.1007/s00382-011-1224-9. [Link]

Kim, H.-M., P. J. Webster, and J. A. Curry, 2011: Modulation of North Pacific tropical cyclone activity by three phases of ENSO. J. Climate, 24, 1839-1849, doi: 10.1175/2010jcli3939.1. [Link]

Korty, R. L., S. J. Camargo, and J. Galewsky, 2012: Tropical cyclone genesis factors in simulations of the last glacial maximum. J. Climate, 25, 4348-4365, doi: 10.1175/jcli-d-11-00517.1. [Link]

Kotal, S. D., P. K. Kundu, and S. K. Roy Bhowmik, 2009: Analysis of cyclogenesis parameter for developing and nondeveloping low-pressure systems over the Indian Sea. Nat. Hazards, 50, 389-402, doi: 10.1007/s11069009-9348-5. [Link]

Kug, J.-S., F.-F. Jin, and S.-I. An, 2009: Two types of El Niño events: Cold Tongue El Niño and Warm Pool El Niño. J. Climate, 22, 1499-1515, doi: 10.1175/2008JCLI2624.1. [Link]

Lander, M. A., 1994: An exploratory analysis of the relationship between tropical storm formation in the western North Pacific and ENSO. Mon. Weather Rev., 122, 636-651, doi: 10.1175/1520-0493(1994)122<0636:AE AOTR $>2.0 . \mathrm{CO} ; 2$. [Link]

Ma, J. and J.-Y. Yu, 2014: Linking centennial surface warming patterns in the Equatorial Pacific to the relative strengths of the Walker and Hadley circulations. J. Atmos. Sci., 71, 3454-3464, doi: 10.1175/JASD-14-0028.1. [Link]

Molinari, J. and D. Vollaro, 2013: What percentage of western North Pacific tropical cyclones form within the monsoon trough? Mon. Weather Rev., 141, 499-505, doi: 10.1175/mwr-d-12-00165.1. [Link]

Murakami, H. and B. Wang, 2010: Future change of North Atlantic tropical cyclone tracks: Projection by a $20-\mathrm{km}-$ mesh global atmospheric model. J. Climate, 23, 2699-
2721, doi: 10.1175/2010jcli3338.1. [Link]

Murakami, H., Y. Wang, H. Yoshimura, R. Mizuta, M. Sugi, E. Shindo, Y. Adachi, S. Yukimoto, M. Hosaka, S. Kusunoki, T. Ose, and A. Kitoh, 2012: Future changes in tropical cyclone activity projected by the new highresolution MRI-AGCM. J. Climate, 25, 3237-3260, doi: 10.1175/jcli-d-11-00415.1. [Link]

Ren, H.-L. and F.-F. Jin, 2011: Niño indices for two types of ENSO. Geophys. Res. Lett., 38, doi: 10.1029/2010GL046031. [Link]

Royer, J. F., F. Chauvin, B. Timbal, P. Araspin, and D. Grimal, 1998: A GCM study of the impact of greenhouse gas increase on the frequency of occurrence of tropical cyclones. Clim. Change, 38, 307-343, doi: 10.1023/A:100538631. [Link]

Tippett, M. K., S. J. Camargo, and A. H. Sobel, 2011: A Poisson regression index for tropical cyclone genesis and the role of large-scale vorticity in genesis. J. Climate, 24, 2335-2357, doi: 10.1175/2010jcli3811.1. [Link]

Trenberth, K. E., 1990: Recent observed interdecadal climate changes in the northern hemisphere. Bull. Amer. Meteorol. Soc., 71, 988-993, doi: 10.1175/1520-0477(1990)071<0988:ROICCI>2.0. $\mathrm{CO} ; 2$. [Link]

Wang, B. and J. C. L. Chan, 2002: How strong ENSO events affect tropical storm activity over the western North Pacific. J. Climate, 15, 1643-1658, doi: 10.1175/1520-0442(2002)015<1643:HSEEAT>2.0. $\mathrm{CO} ; 2$. [Link]

Wang, B. and Q. Zhang, 2002: Pacific-East Asian teleconnection. Part II: How the Philippine Sea anomalous anticyclone is established during $\mathrm{El}$ Niño development. J. Climate, 15, 3252-3265, doi: 10.1175/1520-0442(2002)015<3252:PEATPI $>2.0$. CO;2. [Link]

Wang, B., R. Wu, and X. Fu, 2000: Pacific-East Asian Teleconnection: How Does ENSO Affect East Asian Climate? J. Climate, 13, 1517-1536, doi: 10.1175/1520-0442(2000)013<1517:PEATHD $>2.0$. CO;2. [Link]

Wang, C. and B. Wang, 2019: Tropical cyclone predictability shaped by western Pacific subtropical high: Integration of trans-basin sea surface temperature effects. Clim. Dyn., 53, 2697-2714, doi: 10.1007/s00382-01904651-1. [Link]

Wang, C., B. Wang, and L. Wu, 2019: Abrupt breakdown of the predictability of early season typhoon frequency at the beginning of the twenty-first century. Clim. Dyn., 52, 3809-3822, doi: 10.1007/s00382-018-43509. [Link]

Wu, L., Z. Wen, R. Huang, and R. Wu, 2012: Possible linkage between the monsoon trough variability and the tropical cyclone activity over the western North Pacific. 
Mon. Weather Rev., 140, 140-150, doi: 10.1175/mwrd-11-00078.1. [Link]

Wu, L., C. Wang, and B. Wang, 2015: Westward shift of western North Pacific tropical cyclogenesis. Geophys. Res.Lett.,42,1537-1542,doi: 10.1002/2015GL063450. [Link]

Xiang, B., B. Wang, W. Yu, and S. Xu, 2013: How can anomalous western North Pacific Subtropical High intensify in late summer? Geophys. Res. Lett., 40, 23492354, doi: 10.1002/grl.50431. [Link]

Yu, J.-Y. and C.-W. Chang, 2014: Anatomizing the ocean's role in maintaining the Pacific decadal variability. $A d v$. Atmos. Sci., 31, 611-623, doi: 10.1007/s00376-0133032-0. [Link]

Yu, J.-Y. and P.-G. Chiu, 2012: Contrasting various metrics for measuring tropical cyclone activity. Terr. Atmos. Ocean. Sci., 23, 303-316, doi: 10.3319/ TAO.2011.11.23.01(A). [Link]

Yu, J.-Y., C. Chou, and P.-G. Chiu, 2009: A revised accumulated cyclone energy index. Geophys. Res. Lett., 36, L14710, doi: 10.1029/2009GL039254. [Link]

Yu, J.-Y., L.-P. Hsiao, and P.-G. Chiu, 2018: Evaluating the Emanuel-Nolan genesis potential index: Contrast between North Atlantic and western North Pacific. Terr. Atmos. Ocean. Sci., 29, 201-214, doi: 10.3319/ TAO.2017.09.27.01. [Link]

\section{APPENDIX}

\section{A. Lag Correlation Analysis Between MEI and NTC}

Figure A1 analyzes the lag correlation pattern between the time series of MEI (multivariate ENSO index) and NTC (number of tropical cyclone) for both the first-half-year (in blue) and the second-half-year (in orange) periods. As anticipated, NTC is negatively correlated to MEI during the first-half-year period. The magnitude of correlation tends to increase when MEI leads NTC for months. For example, the correlation coefficients are all below - 0.4 (i.e., stronger negative correlation) from lead months 1 to 9 , with the peak magnitude of -0.48 occurring at lead month 7 , and weaken rapidly form lead months 10 to 12 . The results clearly indicate that TC genesis frequency can be significantly suppressed for more than two seasons (i.e., from early spring to early summer) in the WNP after maturity of an ENSO event. In contrast, the correlation between MEI and NTC is positive but relatively small (all below 0.2) during the second-half-year period, implying a modest modulation of TC genesis frequency in the WNP during the ENSO developing phase.

\section{B. Circulation Changes in the first-half years of 1983, 1998, and 2016}

Figure B1 displays changes in $850 \mathrm{hPa}$ winds and mid- level moisture (see left panels) respectively in the first-half years of 1983,1998 , and 2016 . The $850 \mathrm{hPa}$ rotational part of winds (denoted by stream function) during the first-half year of 1983 (Fig. B1a) shows a strong anticyclonic anomaly in the WNP, providing a drier-than-normal environment disfavoring TC genesis potential in the WNP. The divergent part of winds (denoted by velocity potential) during the first-half year of 1983 (Fig. B1b) suggests that this lowlevel anticyclonic anomaly is a response of the descending branch of a northwest-and-southeast tilting anomalous overturning circulation (Walker circulation) spanning the entire tropical Pacific. We note that the anomalous circulation patterns in the first-half year of 1998 (Figs. B1c and B1d) are very similar to those of 1983 . However, the anomalous circulation patterns in the first-half year of 2016 shows a somewhat different picture compared to the previous two cases. For instance, the Philippine Sea anticyclone is split into two centers in 2016 (Fig. B1e), with one within the MDR centered at $\left(15^{\circ} \mathrm{N}, 127.5^{\circ} \mathrm{E}\right)$ and the other outside the MDR centered at $\left(25^{\circ} \mathrm{N}, 160^{\circ} \mathrm{E}\right)$. Besides, the anomalous overturning circulation (Walker circulation) in 2016 is much weaker and narrower (Fig. B1f) although the descending branch of the overturning circulation is located within the MDR similar to those in 1983 and 1998. In summary, all three cases confirm the suppression of TC activity in the WNP due to the existence of a Philippine Sea anticyclonic anomaly linked to a northwest-and-southeast tilting anomalous overturning (Walker) circulation across the tropical Pacific basin after maturity of strong El Niño events.

\section{Results from the Emanuel-Noland Genesis Potential Index}

Emanuel and Nolan (2004) proposed a "genesis potential index" (GPI) to describe the nonlinear multiplication of four environmental factors in favor of TC genesis:

GPI $=\left|10^{5} \eta\right|^{3 / 2}\left(\frac{\mathrm{RH}}{50}\right)^{3}\left(\frac{\mathrm{V}_{\text {pot }}}{70}\right)^{3}\left(1+0.1 \mathrm{~V}_{\text {shear }}\right)^{-2}$

where $\eta$ is the absolute vorticity at $850 \mathrm{hPa}$ (in units of $\mathrm{s}^{-1}$ ), RH is the relative humidity at $700 \mathrm{hPa}$ (in units of \%), $\mathrm{V}_{\text {shear }}$ denotes magnitude of vertical wind shear between 850 and $200 \mathrm{hPa}$, and $\mathrm{V}_{\text {pot }}$ represents the maximum potential intensity of tropical cyclone (both in units of $\mathrm{m} \mathrm{s}^{-1}$ ). The detailed description of $\mathrm{V}_{\text {pot }}$ can be found in Bister and Emanuel (2002).

Following a similar approach as in section 2.2 for the "seasonal genesis parameter", the anomaly equation governing Emanuel-Nolan GPI changes can be expressed as

$\mathrm{cGPI}^{\prime}=\mathrm{cETA}^{\prime}+\mathrm{cRH}^{\prime}+\mathrm{cVpot}^{\prime}+\mathrm{cVshear}{ }^{\prime}$

where $\mathrm{cGPI}^{\prime}=\log _{2}\left(\frac{\mathrm{GPI}}{\overline{\mathrm{GPI}}}\right), \mathrm{cETA}^{\prime}=\log _{2}\left(\frac{\left|10^{5} \eta\right|^{3 / 2}}{\left|10^{5} \bar{\eta}\right|^{3 / 2}}\right)$, and 


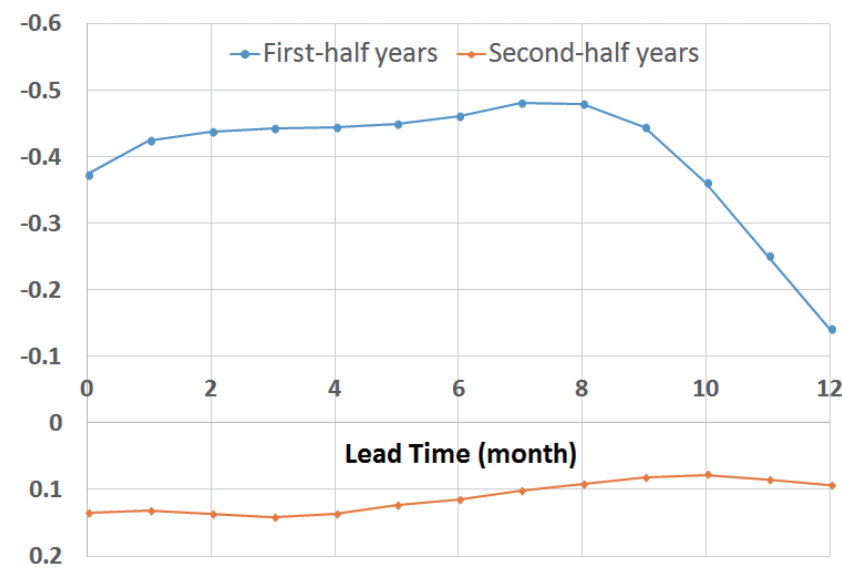

Fig. A1. Correlation coefficient between the time series of MEI and NTC. The numbers on the abscissa denote the lead time (in month) of MEI relative to NTC in conducting the correlation analysis.

(a) $1983 \mathrm{RH} /$ Rotational Winds Anomaly

850hPa Rotational winds

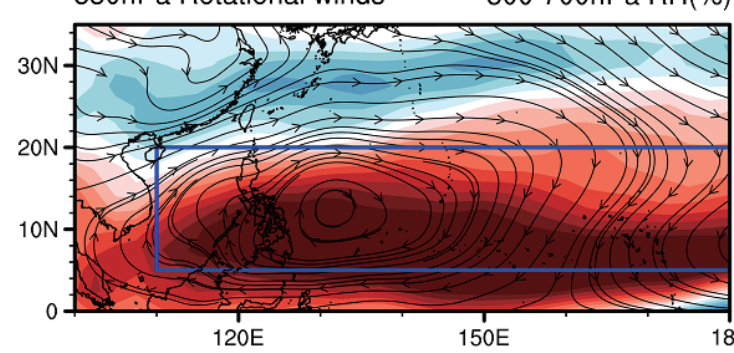

(c) 1998 RH / Rotational Winds Anomaly

$850 \mathrm{hPa}$ Rotational winds

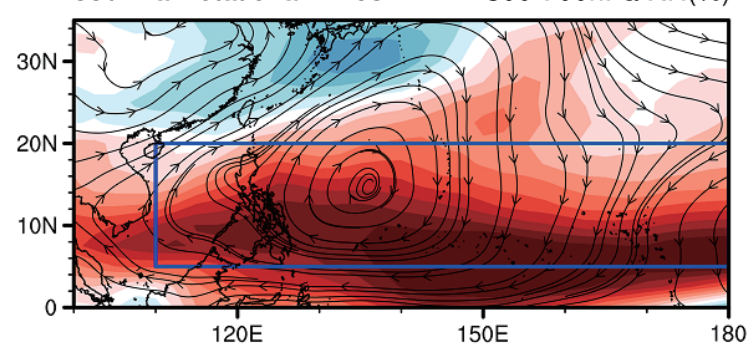

(e) 2016 RH / Rotational Winds Anomaly

850hPa Rotational winds $\quad 500-700 \mathrm{hPa} \mathrm{RH}(\%)$

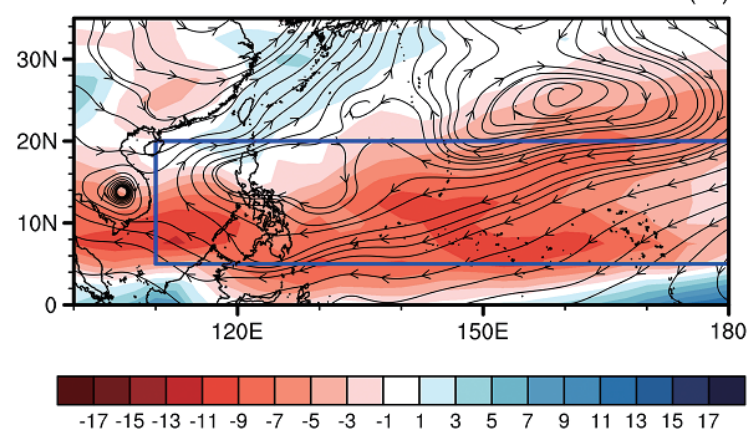

(b) 1983 Velocity Potential Anomaly

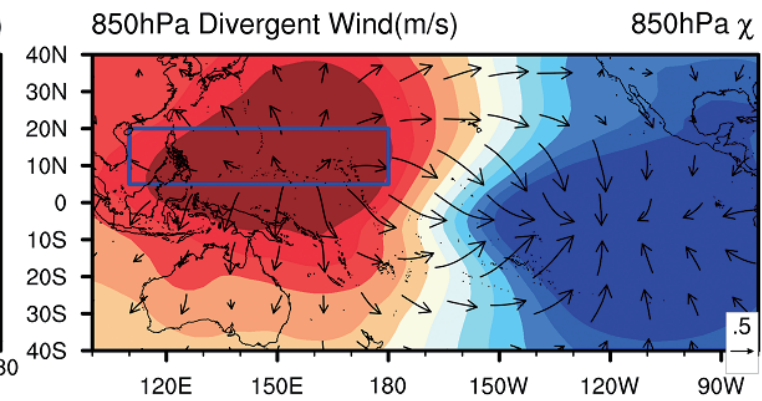

(d) 1998 Velocity Potential Anomaly

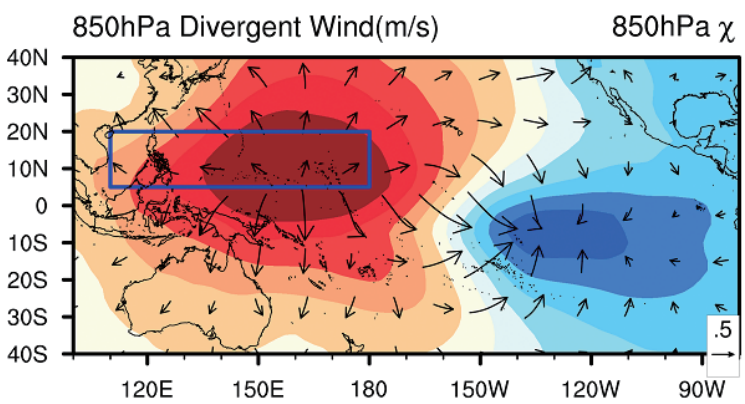

(f) 2016 Velocity Potential Anomaly

850hPa Divergent Wind $(\mathrm{m} / \mathrm{s}) \quad$ 850hPa $\chi$

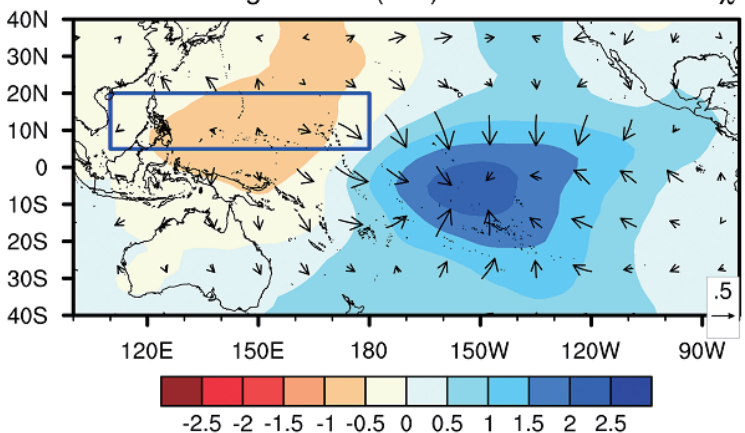

Fig. B1. Same as Fig. 4, but for anomalies of (a) (c) (e) $850 \mathrm{hPa}$ stream function (contours) and 500 - $700 \mathrm{hPa}$ relative humidity (shadings) and (b) (d) (f) $850 \mathrm{hPa}$ velocity potential (shadings) and divergent winds (vectors), respectively, over the first-half-year periods (January to June) of 1983 , 1998, and 2016. The rectangular boxes mark the domain of MDR. 
so on. Likewise, a positive (negative) value of cGPI' denotes an above-normal (below-normal) condition of the TC genesis potential, with a value determined by the four effects on the right-hand-side of Eq. (C2).

Figure $\mathrm{C} 1$ shows the time series of cGPI' and the contribution due to change in absolute vorticity ( $\left.\mathrm{cETA}^{\prime}\right)$, relative humidity $\left(\mathrm{cRH}^{\prime}\right)$, potential intensity $\left(\mathrm{cVpot}^{\prime}\right)$, and vertical wind shear (cVshear'), respectively. As shown, the far-below-normal TC activity in the first-half years of 1983, 1998, and 2016 is successfully captured by the Emanuel-Nolan GPI. We note that, while the four effects seem to all disfavor the TC formation, over two thirds of the cGPI' amplitude result from change in relative humidity $\left(\mathrm{cGPI}^{\prime}\right)$, indicating the dominance of drying effect in determining the rare TC formation during the aforementioned period. On the other hand, changes in vertical wind shear ( $\left.\mathrm{cVshear}{ }^{\prime}\right)$ and potential intensity ( $\left.\mathrm{cVpot}^{\prime}\right)$ play a secondary role; while contribution from change in absolute vorticity $\left(\mathrm{cETA}^{\prime}\right)$ is very small.

The spatial distribution of cGPI', cETA', $\mathrm{cRH}^{\prime}, \mathrm{cVpot}^{\prime}$, and cVshear' (Fig. C2) also confirms that the suppressed TC formation in the first half years of 1983, 1998, and 2016 is mainly due to change in $\mathrm{cRH}^{\prime}$, with strong negative

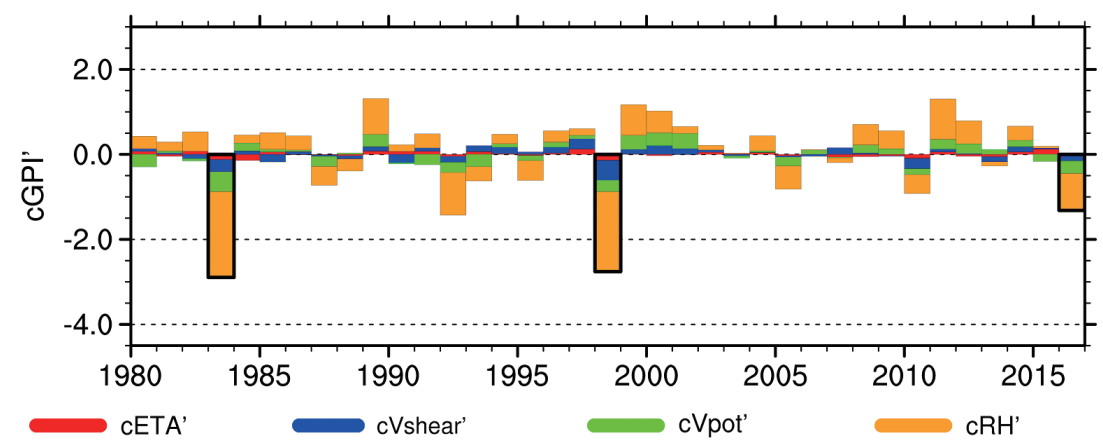

Fig. C1. Same as in Fig. 2, but for the Emanuel-Nolan GPI, with red denoting the absolute vorticity term, blue the vertical wind shear term, green the potential intensity term (by combining SST and atmospheric stability effects), and orange the relative humidity term.

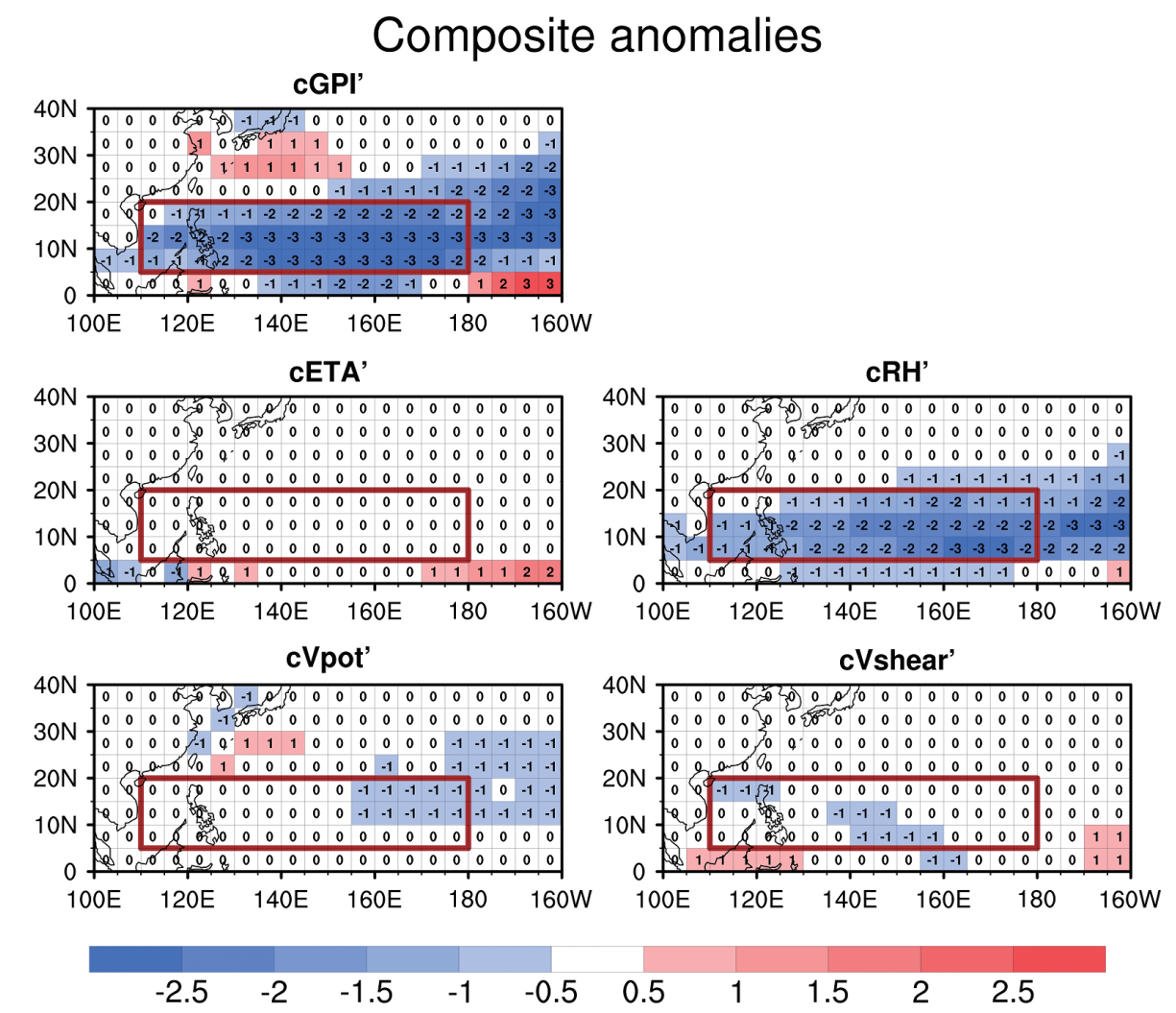

Fig. C2. Same as in Fig. 3, but for the Emanuel-Nolan GPI. The four factors include absolute vorticity ( $\left.\mathrm{cETA}^{\prime}\right)$, relative humidity $\left(\mathrm{cRH}^{\prime}\right)$, potential intensity $\left(\mathrm{cVpot}^{\prime}\right)$, and vertical wind shear $\left(\mathrm{cVshear}^{\prime}\right)$. 
anomalies covering almost the entire MDR region. On the contrary, much weaker anomalies of $\mathrm{cVpot}^{\prime}$ and cVshear' scatter over the WNP. Moreover, the minimal role of absolute vorticity change ( $\left.\mathrm{cETA}^{\prime}\right)$ in determining the amplitude of cGPI' appears to oppose the budget results for SGP in section 3 in which relative vorticity and humidity are shown to be equally important in accounting for SGP anomaly.

The above disagreement can be attributed to different treatments of the vorticity effect. In SGP, relative vorticity and planetary vorticity are two separate factors; while in GPI, they are combined into a single absolute vorticity factor. Since relative vorticity calculated from large-scale winds is an order of magnitude smaller than the planetary vorticity, using absolute vorticity would decrease the sensitivity of relative vorticity effect, resulting in a serious underestimation of the contribution from circulation change. 